\title{
ELECTROPHORETIC VARIANTS OF BLOOD PROTEINS IN JAPANESE VII. CYTOPLASMIC GLUTAMATE-OXALOACETATE TRANSAMINASE (GOT1)
}

\author{
Chiyoko Satoh, Norio Takahashi, Yasukazu Kimura, \\ Akiko Miura, Junko KaneKo, Mikio Fujita \\ and Kyoko ToYAmA ${ }^{1}$ \\ Laboratory of Biochemical Genetics, Department of Genetics, \\ Radiation Effects Research Foundation, 5-2 Hijiyama Park, \\ Minami-Ward, Hiroshima 732, Japan
}

\begin{abstract}
Summary A total of 16,835 children, of whom 11,737 are unrelated, from Hiroshima and Nagasaki were examined for erythrocyte cytoplasmic glutamate-oxaloacetate transaminase (GOT1) by starch gel electrophoresis. A variant allele named $G O T 1 * 2 H R 1$ which seems to be identical with GOTI 2 was encountered in polymorphic frequency. Five kinds of rare variants, 3NG1, 4NG1, 5NG1, 6HR1 and 7NG1 were encountered in a total of 109 children. Except for $7 \mathrm{NGl}$ for which complete family study was unable, family studies confirmed the genetic nature of these rare variants, since for all instances in which both parents could be examined, one of the parents exhibited the same variant as that of their child. Thermostability profiles of these six variants were normal. The enzyme activities of five were decreased, while the value of one was normal compared to that of GOT1 1.
\end{abstract}

\section{INTRODUCTION}

The first paper in this series describes the purpose of the study and circumstances under which the study was performed (Satoh et al., 1984). The present paper, continuing a series reporting results of electrophoretic studies, describes variants of cytoplasmic glutamate-oxaloacetate transaminase [GOT1, EC 2.6.1.1; aspartate aminotransferase] encountered in a total of 16,835 children of atomic bomb survivors from Hiroshima and Nagasaki; a preliminary report of this work was presented earlier (Kimura et al., 1981). Glutamate-oxaloacetate transaminase

Received October 25, 1985

${ }^{1}$ Department of Clinical Studies, Radiation Effects Research Foundation, 8-6, 1-chome, Nakagawa, Nagasaki 850, Japan 
occurs under independent genetic control in two separate forms, cytoplasmic (GOT1) and mitochondrial (GOT2), both forms sometimes occurring as genetic polymorphisms in humans. The alleles $G O T 1^{*} 2$ and $G O T 1^{*} 3$ were observed in polymorphic or appreciable frequencies in Japanese, Chinese, Fillipino and Amerindian populations, while they are very rare in European and black populations (Ishimoto and Kuwata, 1974; Chen and Giblett, 1971). The allele GOT2*2 is present in polymorphic frequency in European populations and in appreciable frequency in black populations (Davidson et al., 1970; Hackel et al., 1972), in a Japanese population (Toyomasu et al., 1984), and in Malays and Chinese populations (Teng et al., 1978). GOT2*3 is polymorphic only in black populations (Davidson et al., 1970; Hackel et al., 1972).

\section{MATERIALS AND METHODS}

The populations, the method of family studies and preparation of the hemolysates for electrophoresis were described earlier (Satoh et al., 1984). A total of 16,835 children (age 13 to 38 ) of A-bomb survivors and controls were examined. Approximately $30 \%$ of these children are siblings.

Vertical starch gel electrophoresis and gel staining for the first screening were performed basically following the method of Chen and Giblett (1971). Electrophoresis was conducted at $4^{\circ} \mathrm{C}$ and 9 volts $/ \mathrm{cm}$ for $18-20 \mathrm{hr}$ employing $13.3 \%$ Connaught starch gel and $0.1 \mathrm{M}$ Tris-citrate buffer, $\mathrm{pH} 7.5$, as bridge buffer and a $1 / 15$ dilution solution ( $\mathrm{pH} 7.5$ ) as gel buffer. The staining mixture consists of $10 \mathrm{ml}$ of $0.1 \mathrm{~m}$ Tris- $\mathrm{HCl}$ buffer, pH 7.8, $350 \mathrm{mg}$ of L-aspartic acid (Na-salt), $30 \mathrm{mg}$ of $\alpha$-ketoglutarate, $10 \mathrm{mg}$ of $\mathrm{NADH}_{2}$ and 100 units of malate dehydrogenase (MDH). Using the filter paper overlay method, gels were incubated at $37^{\circ} \mathrm{C}$ for $30 \mathrm{~min}$. Defluorescent dark bands of GOT1 appeared against a fluorescent background of $\mathrm{NADH}_{2}$. For comparison of variants, a discontinuous buffer system of $\mathrm{pH} 7.5$ (Wurzinger and Mohrenweiser, 1982) as described below was also used. The bridge buffer contained $0.44 \mathrm{M}$ boric acid, $0.04 \mathrm{M}$ Tris and $0.04 \mathrm{M} \mathrm{LiOH}$. The gel buffer contained $0.0124 \mathrm{~m}$ Tris, $0.0036 \mathrm{M}$ boric acid, $0.0033 \mathrm{~m}$ citric acid and $0.00033 \mathrm{M} \mathrm{LiOH}$.

GOT1 activity was determined spectrophotometrically using $10 \mu \mathrm{l}$ of $1: 20$ diluted hemolysates made from packed red cells preserved in liquid nitrogen. Our procedures in general follow the methods of Beutler et al. (1977) and the International Committee for Standardization in Haematology (1967). Final concentrations of the assay mixture components $(500 \mu)$ were the same as those of Beutler et al. (1977), pyridoxal phosphate always being added in a concentration of 0.02 mM. Using an Aminco Rotochem IIa/36, a centrifugal fast analyzer, decrease of optical density of the system at $340 \mathrm{~nm}$ and at $30^{\circ} \mathrm{C}$ was read every 1 min for 10 min after a lag time of $10 \mathrm{~min}$. Enzyme activity was expressed by international units per gram of hemoglobin (IU/gHb). Details of sample preparation and data management were as those described by Satoh et al. (1983). 
Thermostability profiles of variant enzymes were examined as previously described (Satoh et al., 1985) using $1: 20$ diluted hemolysates prepared from packed red cells preserved in liquid nitrogen. Percent remaining activities were determined after heating for 10 and $20 \mathrm{~min}$ at $60^{\circ} \mathrm{C}$.

Variants were named according to the method of Ferrell et al. (1977) except that abbreviations for Hiroshima and Nagasaki are HR and NG, respectively.

\section{RESULTS}

Of 16,835 examined children, 9,040 from Hiroshima and 7,779 from Nagasaki totaling 16,819 children, were clearly typed, employing the Tris-citrate buffer system of Chen and Giblett (1971). Numbers of children with various phenotypes are shown in Table 1. When the phenotype could not be read clearly, 'no type' is indicated. Since approximately $30 \%$ of the total children comprise siblings, the same variant was encountered more than once. The figures in parentheses are numbers of variants excluding those detected in siblings. The 'Representative' population composed of unrelated children was selected from the total children by the method previously described (Satoh et al., 1984) and the allele frequencies are calculated from this population. Since the first child among the siblings to undergo the test was selected as a member of this population, children having variants may not necessarily be members of this population.

Six kinds of variants were detected. The most common variant phenotype was named $1-2 \mathrm{HR} 1$, since its pattern, both mobility and intensity of three bands, is

Table 1. Various phenotypes of GOT1 and allele frequencies among Japanese from Hiroshima and Nagasaki.

\begin{tabular}{|c|c|c|c|c|c|}
\hline \multirow[b]{2}{*}{ Phenotype } & \multirow{2}{*}{$\begin{array}{l}\text { Total children } \\
\text { examined }\end{array}$} & \multicolumn{4}{|c|}{ Representative } \\
\hline & & Combined & Hiroshima & Nagasaki & $\begin{array}{l}\text { Allele frequencies } \\
\text { for the combined }\end{array}$ \\
\hline 1 & 16,250 & 11,341 & 6,450 & 4,891 & \\
\hline 1-2HR1 & 459 & 322 & 205 & 117 & $=0.98309$ \\
\hline 2HR1 & 1 & 1 & 1 & 0 & $G O T I^{*} 2 H R I=0.01380$ \\
\hline 1-3NG1 & $50(36)^{a}$ & 30 & 20 & 10 & $G O T 1^{*} 3 N G 1=0.00128$ \\
\hline $1-4 \mathrm{NG} 1$ & $50(42)$ & 36 & 22 & 14 & $G O T 1 * 4 N G 1=0.00153$ \\
\hline $1-5 \mathrm{NG} 1$ & $4(3)$ & 3 & 1 & 2 & $G O T 1 * 5 N G 1=0.00013$ \\
\hline 1-6HR1 & $4(3)$ & 3 & 2 & 1 & $G O T I^{*} 6 H R I=0.00013$ \\
\hline 1-7NG1 & 1 & 1 & 0 & 1 & $G O T I^{*} 7 N G I=0.00004$ \\
\hline No types & 16 & 0 & 0 & 0 & \\
\hline Total & 16,835 & 11,737 & 6,701 & 5,036 & \\
\hline
\end{tabular}

${ }^{a}$ Figures in parentheses are number of variants excluding those detected in siblings. 
very similar to that of 1-2 shown in the photographs of Chen and Giblett (1971) and Ishimoto and Kuwata (1974), though no direct comparison was performed. It was encountered in a total of 459 children and, in addition, a homozygous phenotype, GOT1 2HR1 was encountered in a Hiroshima child. The frequencies of $G O T I^{*} 2 H R l$ were 0.015 and 0.012 in Hiroshima and in Nagasaki, respectively

Five other rare variants designated $3 \mathrm{NG1}, 4 \mathrm{NG1}, 5 \mathrm{NG} 1,6 \mathrm{HR} 1$ and $7 \mathrm{NG} 1$ were encountered in a total of 109 children as phenotypes heterozygous with 1 . Figure 1 shows the patterns of heterozygous variant phenotypes obtained by electrophoresis using the Tris-citrate buffer system of Chen and Giblett (1971) and Fig. 2 shows them diagrammatically. Electrophoretic characteristics of variants are described below on the basis of patterns obtained with this buffer system unless

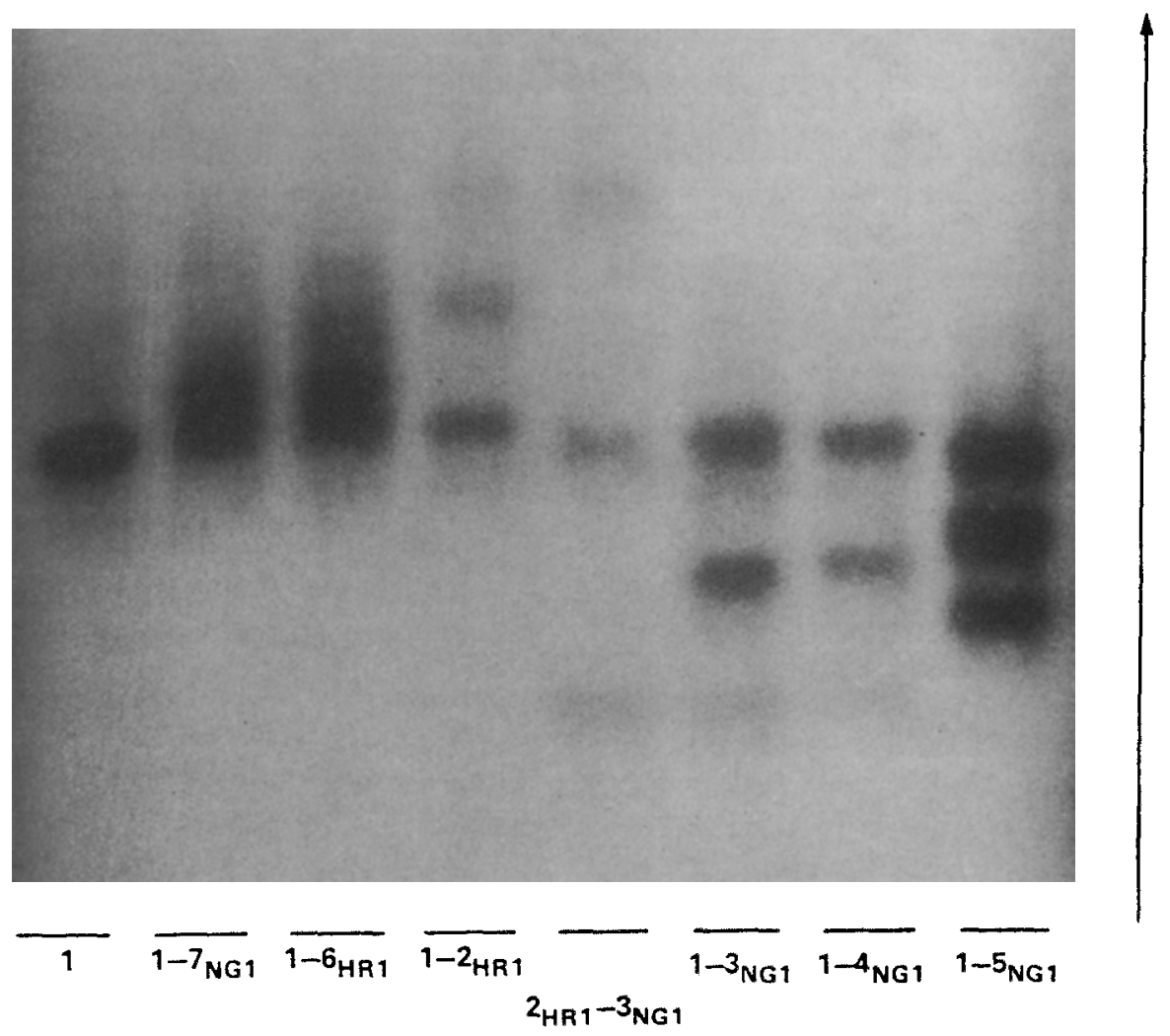

Fig. 1. Patterns of normal and seven variant phenotypes obtained from children and one of their mother by electrophoresis using the Tris-citrate buffer, pH 7.5. Mother of a Nagasaki child having 1-3NG1, showing 2HR1-3NG1. (Fifth lane from the left). 
otherwise described. All of the heterozygous variants are composed of three bands, one corresponding to the major band of 1 and two additional bands. These two additional bands, one considered to be a variant homodimer and the other a variantnormal heterodimer (Chen and Giblett, 1971), in 1-3NG1, 1-4NG1 and 1-5NG1 migrated cathodal to the main band of phenotype 1, while those in 1-6HR1 and 1-7NG1 migrated anodal to the band of 1 . One or two secondary bands appeared to the anodal side of the variant homodimer bands of phenotypes 1-6HR1 and 1-7NG1, and to the main band of phenotype 1. These secondary bands are diagrammatically shown in broken line in Fig. 2.

Mobilities and intensities of the two variant bands of 1-3NG1 and 1-4NG1 were similar to those of 1-3, in which the middle band (the heterodimer) was less intense and the slowest band (the variant homodimer) was the least intense, as reported by Chen and Giblett (1971) and Ishimoto and Kuwata (1974). The middle and slowest bands of 1-3NG1 migrated slightly cathodal to those of 1-4NG1, respec-

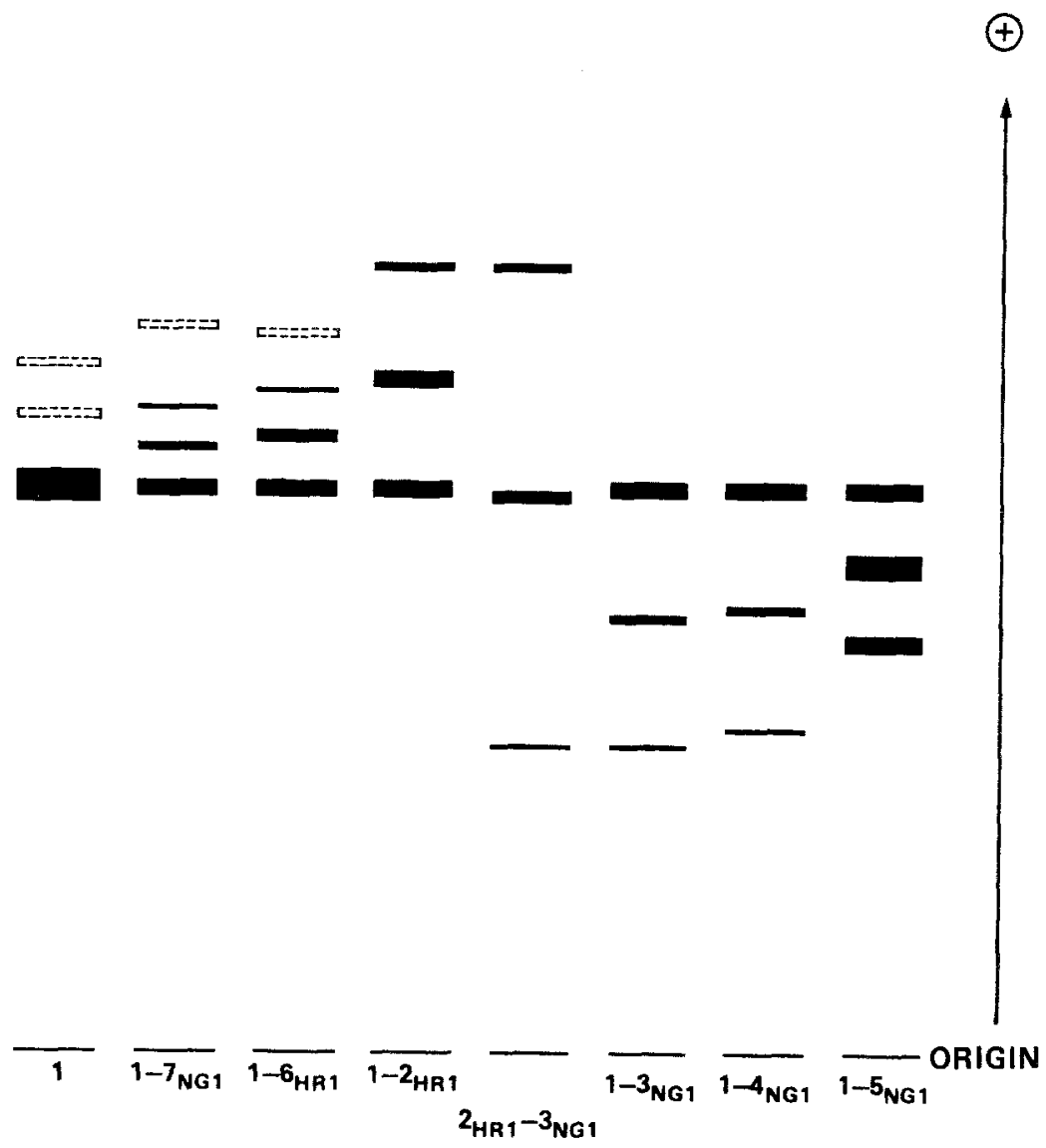

Fig. 2. Diagram of seven variant phenotypes on starch gel using the Tris-citrate buffer system, pH 7.5. 
tively. 1-3NG1 was encountered in 27 Hiroshima children (21 unrelated children) and 23 Nagasaki children (15 unrelated children). 1-4NG1 was found in 28 Hiroshima children (24 unrelated children) and 22 Nagasaki children (18 unrelated children). The frequencies of GOTI*3NGl in Hiroshima and Nagasaki are 0.0015 and 0.0010 , respectively and those of $G O T l^{*} 4 N G l$ are 0.0016 and 0.0014 , respectively. Since difference in mobility of the variant homodimer band between $3 \mathrm{NG1}$ and 4NGI and that in allele frequency between GOT1*3NGI and GOTI*4NG1 were very slight, and we did not directly compare them with $1-3$, it is difficult to determine which of them is the same as 1-3 or whether both of them are different from 1-3. In a family study for a Nagasaki child with 1-3NG1, father was type 1 and mother showed $2 \mathrm{HR} 1-3 \mathrm{NG}$ in which the position of the middle band was very slightly cathodal to that of the main band of phenotype 1 . The same phenomenon was observed in photograph of 2-3 in the report of Ishimoto and Kuwata (1974).

Since Wurzinger and Mohrenweiser (1982) succeeded in classifying two kinds of slow variants into five subtypes with a discontinuous buffer system of $\mathrm{pH} 7.5$, we examined all the cases of variants with this buffer system. Results are shown

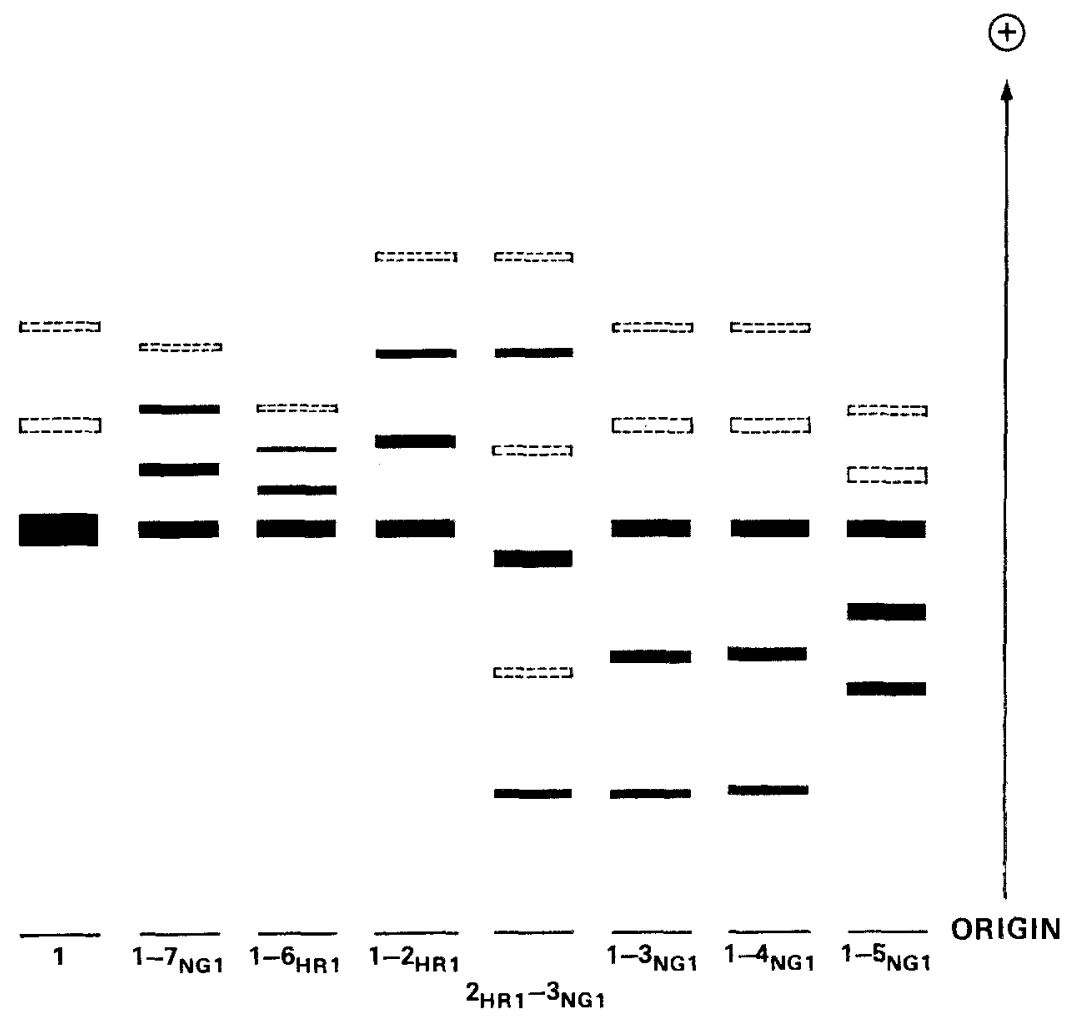

Fig. 3. Diagram of seven variant phenotypes on starch gel using the discontinuous buffer system, pH 7.5 . 
diagrammatically in Fig. 3. In addition to ordinary three bands of 1-3NG1, 1$4 \mathrm{NGI}$ or $1-5 \mathrm{NG} 1$, two to three bands appeared to the anodal side of the normal homodimer band but no new class of variants were encountered among them. Moreover, we found that the difference in the mobility of the homodimer band between $3 \mathrm{NG} 1$ and $4 \mathrm{NG1}$ in this buffer system is smaller than that in the Triscitrate buffer system. On the basis of the migration rate observed in this buffer system, 2HR1 and $3 \mathrm{NG1}$ or $4 \mathrm{NG1}$ seem to correspond to $2 \mathrm{~A}$ and $3 \mathrm{~A}$, respectively, of Wurzinger and Mohrenweiser (1982) encountered in individuals of Oriental ancestry: the ratio of the distance between the homodimer band of $2 \mathrm{HR} 1$ and the homodimer band of 1 in the 1-2HR1 pattern to that between the homodimer band of $3 N G 1$ or $4 N G 1$ and the homodimer band of 1 in the 1-3NG1 or 1-4NG1 pattern was the same as the ratio of that in the 1-2A to that in the 1-3A shown in their diagram. Since the difference in the mobility between the homodimer band of $3 \mathrm{NG} 1$ and that of $4 \mathrm{NG} 1$ is very slight in this buffer system, it is difficult to decide which of them corresponds to $3 \mathrm{~A}$.

The most cathodal band of 1-5NG1 showed the same intensity as that of 1 and migrated to a position slightly cathodal to that of the middle band of 1-3NG1. The intensity of the middle band of 1-5NG1 was stronger than those of the other two bands. This variant was encountered once in Hiroshima and three times (two unrelated individuals and a sister of one of them) in Nagasaki. In the forth variant, 1-6HR1, the most anodal band migrated slightly cathodal to the position of the middle band of 1-2HR1 and its intensity was slightly weaker than that of band 1 . This variant was encountered in two unrelated Hiroshima children and two Nagasaki siblings. The fifth rare variant phenotype of 1-7NG1 of which the most anodal variant band migrated slightly cathodal to that of $1-6 \mathrm{HR} 1$ and to the middle band of 1-2HR1 was encountered in a Nagasaki child. Nevertheless, when electrophoresis of 1-2HR1, 1-6HR1 and 1-7NG1 was carried out using the discontinuous buffer system of $\mathrm{pH} 7.5$, four to five bands appeared for each of them. The difference in mobility of each of the bands between 1-2HR 1 and 1-6HR1 or between 1-2HR1 and 1-7NG1 was smaller than that observed using the Tris-citrate buffer. In addition, the order of migration from the anodal side in the discontinuous buffer system was $2 \mathrm{HR} 1>7 \mathrm{NG1}>6 \mathrm{HR} 1$ while that in the Tris-citrate buffer system was $2 \mathrm{HR} 1>$ $6 \mathrm{HR} 1>7 \mathrm{NG} 1$.

Results of family studies for rare variants are summarized in Tables 2, 3, and 4. For all instances in which both parents could be examined, one of the parents exhibited the same variant as that of the propositus. Even in five cases (one case of $3 \mathrm{NG1}$ and four cases of $4 \mathrm{NGl}$ ) where only one parent could be examined, the variant was encountered in that parent. Thus, the genetic nature of $3 \mathrm{NG1}$, 4NG1, $5 \mathrm{NG} 1$ and $6 \mathrm{HR} 1$ was confirmed in most of the cases. Concerning $7 \mathrm{NG} 1$, although the propositus exhibited the phenotype $1-7 \mathrm{NGl}$ in two samples obtained in two different occasions, its genetic nature has not yet been confirmed since the father showed phenotype 1 but the mother could not been examined. 
Table 2. Family studies for GOT1 1-3NG1.

\begin{tabular}{|c|c|c|c|c|}
\hline \multicolumn{3}{|c|}{ Propositus } & \multirow{2}{*}{ Mother } & \multirow{2}{*}{ Father } \\
\hline Combined & Hiroshima & Nagasaki & & \\
\hline 1 & 1 & 0 & 9 & $\delta$ \\
\hline 18 & 11 & 7 & 9 & $\sigma^{x}$ \\
\hline 11 & 6 & 5 & q & $d$ \\
\hline 1 & 0 & 1 & 9 & Dead \\
\hline 5 & 3 & 2 & NT & NT \\
\hline $\begin{array}{ll}7 & \text { Homoz } \\
\mathbf{q}, \mathbf{d} & \text { Hetero } \\
9, \mathbf{0} & \text { Homoz } \\
\text { NT } & \text { Not tes }\end{array}$ & $\begin{array}{l}\text { te for GOT1 } \\
\text { te for GOT1 } \\
\text { te for normal }\end{array}$ & & & \\
\hline
\end{tabular}

Table 3. Family studies for GOT1 1-4NG1.

\begin{tabular}{|c|c|c|c|c|}
\hline \multicolumn{3}{|c|}{ Propositus } & \multirow{2}{*}{ Mother } & \multirow{2}{*}{ Father } \\
\hline Combined & Hiroshima & Nagasaki & & \\
\hline 1 & 0 & 1 & 9 & $\sigma$ \\
\hline 15 & 9 & 6 & $q$ & d \\
\hline 13 & 8 & 5 & q & $\sigma$ \\
\hline 3 & 2 & 1 & 9 & NT \\
\hline 1 & 1 & 0 & $\Phi$ & Dead \\
\hline 8 & 4 & 4 & NT & $\mathrm{NT}$ \\
\hline 1 & 0 & 1 & NT & Dead \\
\hline
\end{tabular}

9, $\delta$ Heterozygote for GOTI*4NG1

क, od Homozygote for GOTI ${ }^{* 1}$

NT Not tested

GOT1 activities of variants were determined when blood samples were available from family studies. Means and standard deviations (SDs) for GOT1 activities obtained from propositi, affected parents and normal parents from Hiroshima are summarized in Table 5. The means and the SDs for type 1 and type 1-2HR1 were obtained from 3,505 and 113 Hiroshima children, respectively, examined in screening for deficiency variants of red cell enzymes; a part of these data have already been reported (Satoh et al., 1983). Inasmuch as Wurzinger and Mohrenweiser (1982) presented data that the level of erythrocyte GOT1 1 activity of non-pregnant females (five individuals) is 1.3 times higher than that of males (thirteen individuals), we calculated the means and SDs by sex: mean \pm SD (IU/gHb) for type 1 from 1,802 females and 1,703 males are $4.52 \pm 0.66$ and $4.73 \pm 0.66$, respectively, for type $1-2 \mathrm{HR} 1$ from 52 females and 61 males are $3.68 \pm 0.49$ and $3.81 \pm 0.50$, respectively. In addi- 
Table 4. Family studies for GOT1 variants.

\begin{tabular}{|c|c|c|c|c|c|c|}
\hline \multicolumn{5}{|c|}{ Propositus } & \multirow{2}{*}{ Mother } & \multirow{2}{*}{ Father } \\
\hline $\begin{array}{c}\text { Variant } \\
\text { No. }\end{array}$ & $\begin{array}{c}\text { Variant } \\
\text { Type }\end{array}$ & City & $\begin{array}{l}\text { ID } \\
\text { No. }\end{array}$ & Sex & & \\
\hline 1 & $5 \mathrm{NG} 1$ & $\mathrm{~N}$ & 681657 & $\mathrm{~F}_{1}$ & $q$ & d \\
\hline 2 & 5NG1 & $\mathrm{N}$ & 681659 & $\mathrm{~F}^{l}$ & & \\
\hline 3 & $5 \mathrm{NG} 1$ & $\mathbf{N}$ & 718532 & $\mathrm{~F}$ & 우 & $\sigma^{*}$ \\
\hline 4 & $5 \mathrm{NGl}$ & $\mathrm{H}$ & 918887 & $\mathrm{~F}$ & NT & NT \\
\hline 5 & $6 \mathrm{HR} 1$ & $\mathrm{~N}$ & 705392 & $\mathrm{~F}_{1}$ & NT & $N T$ \\
\hline 6 & 6HR1 & $\mathrm{N}$ & 705393 & $F^{J}$ & INI & $\mathrm{N}$ \\
\hline 7 & 6HR1 & $\mathrm{H}$ & 402717 & $F$ & 9 & $\sigma^{\star}$ \\
\hline 8 & 6HRI & $\mathrm{H}$ & 919318 & F & NT & NT \\
\hline 9 & 7NG1 & $\mathrm{N}$ & 143543 & M & NT & $\sigma^{*}$ \\
\hline
\end{tabular}

9, Heterozygote for variant alleles at GOTI locus

\$, $\delta$ Homozygote for normal GOTI*I

NT Not tested

1 Siblings

Table 5. Activities (IU/gHb) of various GOT1 variants encountered in Hiroshima children and their parents.

\begin{tabular}{|c|c|c|c|c|c|c|}
\hline \multirow[b]{2}{*}{ Phenotype } & \multicolumn{2}{|c|}{ Propositus } & \multicolumn{2}{|c|}{ Affected parent } & \multicolumn{2}{|c|}{ Normal parent } \\
\hline & Number & $\begin{array}{c}\text { Activity } \\
(\text { Mean } \pm S D)\end{array}$ & Number & $\begin{array}{c}\text { Activity } \\
(\text { Mean } \pm \text { SD) }\end{array}$ & Number & $\begin{array}{c}\text { Activity } \\
(\text { Mean } \pm \text { SD })\end{array}$ \\
\hline 1 & 3,505 & $4.63 \pm 0.67$ & & & & \\
\hline 1-2HR1 & 113 & $3.75 \pm 0.49$ & 10 & $3.05 \pm 0.33$ & 10 & 4. $12 \pm 0.41$ \\
\hline 2HR1 & 1 & 2. 09 & $2^{a}$ & $2.53 \pm 0.20$ & 0 & \\
\hline 1-3NG1 & 9 & $3.20 \pm 0.32$ & 4 & $3.49 \pm 0.93$ & 4 & $4.37 \pm 0.42$ \\
\hline 1-4NG1 & 15 & $3.30 \pm 0.51$ & 11 & $3.64 \pm 0.81$ & 9 & $4.52 \pm 0.64$ \\
\hline $1-5 \mathrm{NG} 1$ & 1 & 4.56 & & & & \\
\hline $1-6 \mathrm{HR} 1$ & 2. & $3.06 \pm 0.10$ & 1 & 3.64 & 1 & 3.23 \\
\hline
\end{tabular}

a Both parents showed 1-2HR1.

tion to these values, we observed that the differences in the means of the activities of other variant phenotypes between the females and males were less than 1SD (data not shown). Thus, our data show no difference by sex for the activity of GOT1, and therefore the means shown in Table 5 were obtained by combining values from both sexes in Hiroshima. Activities of propositi having heterozygous phenotypes such as 1-2HR1, 1-3NG1, 1-4NG1 and 1-6HRI as well as those of affected parents were between $70 \%$ and $80 \%$ of the mean value of type 1 , while normal parents showed normal levels of activity. The activity of 1-7NG1 in a Nagasaki child was $2.90 \mathrm{IU} / \mathrm{gHb}$, or $66 \%$ of the mean value $(4.38 \mathrm{IU} / \mathrm{gHb})$ obtained from 427 Nagasaki 
children having type 1 . On the other hand, the activity of 1-5NG1 from a Hiroshima child was normal. The activity of 1-5NG1 in three Nagasaki children (two siblings and one unrelated child) and their carrier parents was also normal. These observations are consistent with those concerning intensities of variant bands in the above described variants where the band of variant homodimer was the least intense of the three bands and that of the heterodimer was less intense than the homodimer band of 1 , except for $1-5 \mathrm{NG} 1$ where the intensity of the variant homodimer band which is the most cathodal, was as strong as that of homodimer band of 1 .

Regarding the thermostability of GOT1 variants, we have already reported that phenotypes 1-2HR1, 1-3NG1 and 1-4NG1 have normal or increased thermostability (Satoh et al., 1985). Family studies for these variants confirmed the genetic nature of this characteristic, as shown in Table 6. In addition, normal or increased thermostability has been encountered in three new variants, 1-5NG1, 1-6HR1 and 1-7NG1.

Wurzinger and Mohrenweiser (1982) observed the difference in thermostability of GOT1 1 phenotype by sex and were able to subtype electrophoretic variants on the basis of thermostability profiles. Therefore, we calculated by sex the means and SDs of the percent remaining activities observed in our experiments of various phenotypes. Results are shown in Table 6. Moreover, the thermostability profiles of samples in each variant class were carefully compared though our conditions for determining thermostability profiles were different from those of Wurzinger and Mohrenweiser (1982). Finally, thermostability profiles of small number of samples were examined under their conditions (10 males and 10 females of phenotype 1, three samples of type 1-2HR1, two each for 1-3NGl and 1-4NG1). Neither sex difference nor subtypes were observed for phenotype 1 or the electrophoretically variant phenotypes. With regard to subtypes, it is worth noting that the variants of Wurzinger and Mohrenweiser (1982) were present in a heterogeneous American population composed of different ethnic groups while our variants occurred in polymorphic or appreciable frequencies in two Japanese populations which are much more homogeneous. It seems likely that rare variants encountered in different ethnic groups are products of different alleles arising from different mutations and that the Japanese variants are products of identical alleles caused by single mutations which subsequently spread in the population.

\section{DISCUSSION}

Wurzinger and Mohrenweiser (1982) reported that cord blood erythrocyte GOT1 activity was 1.3 times the activity in erythrocyte from pregnant females, 1.5 times the activity in non-pregnant females and 2.0 times the activity in males. The cord blood-adult blood disparities were thought to be related to cell age (Sass et al., 1964; Gahr et al., 1979; Mohrenweiser et al., 1981), while those between pregnant females and normal adults were related to increased vitamin B6 (pyridoxine) intake 


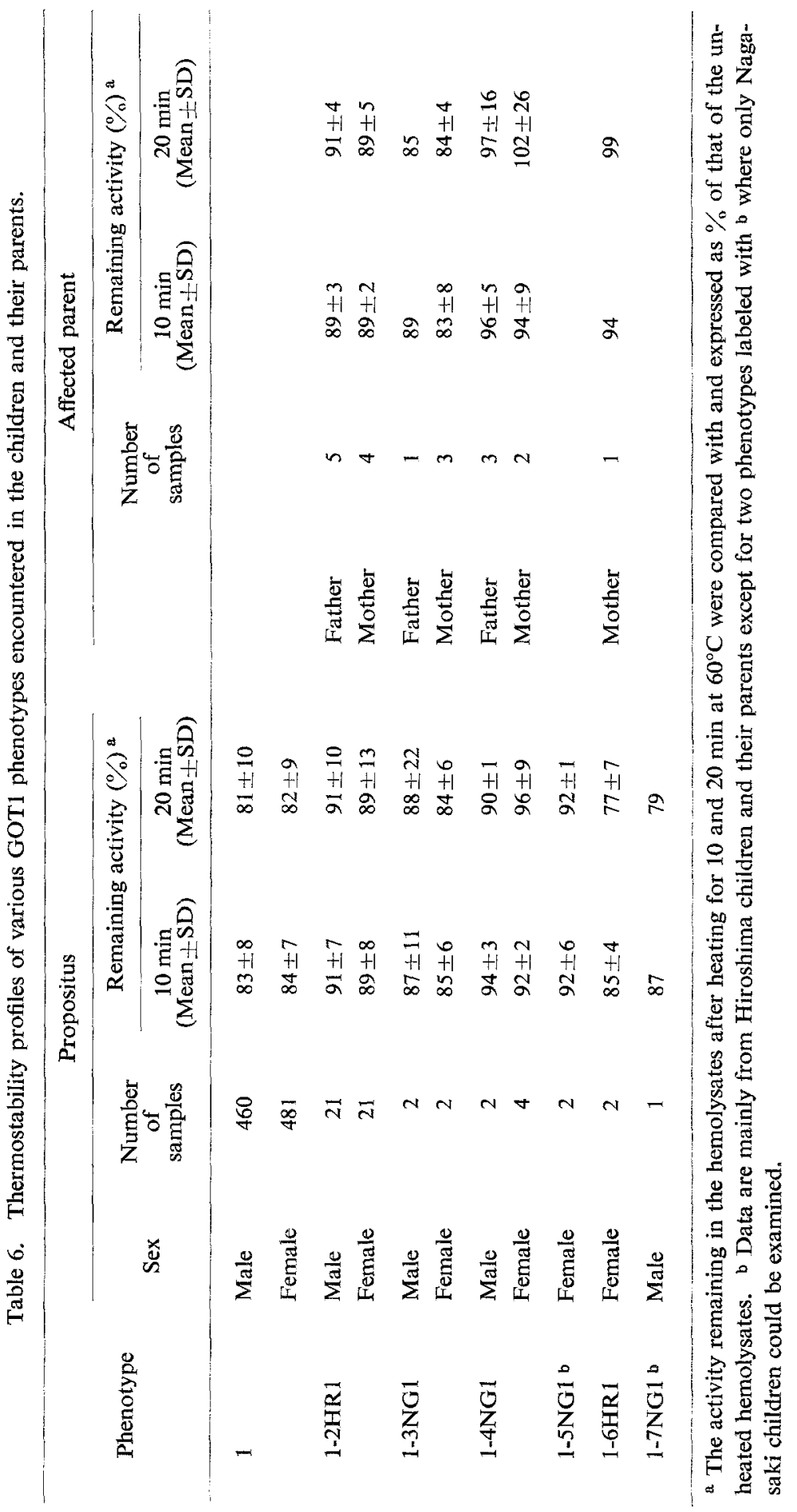


of the pregnant females which would raise the GOT1 levels (Raica and Sauberlich, 1964; Cinnamon and Beaton, 1970), since pyridoxal phosphate serves as a cofactor for the activity of GOT. These authors suggested that the differences between non-pregnant females and males might be connected to the fact that oral contraceptives taken with oral supplementation of vitamin B6 increase erythrocyte GOT levels to a greater degree than oral intake of vitamin B6 alone (Bossé and Donald, 1979). They also reported differences in thermostability of erythrocyte GOT1 among samples from the above described four groups. We were unable to confirm the differences in activity level and thermostability of erythrocyte GOT1 between Japanese males and females for either the normal phenotype or the electrophoretically variant phenotypes. The fact that oral contraceptives are not available in Japan may explain the different observations concerning the activity level and thermostability of GOT1 between the Americans and the Japanese.

Activities of variant phenotypes other than 1-5NGl were lower than that of phenotype 1, while the thermostability profiles of variant GOT1 were normal or stable. This indicates that asymmetry in the triple banded patterns of the variants other than 1-5NG1 is not caused by differences in stability but may be due to either decreased synthesis or lower specific activity of the variant enzyme proteins.

Polymorphic occurrence of $G O T I^{*} 2$ and $G O T I^{*} 3$ in Mongoloid populations were reported by Chen and Giblett (1971) though the population size was small. They reported that allele $G O T I^{*} 2$ was observed in six populations, the highest frequency being 0.056 observed in 188 Canadian Indians. The allele GOTI*3 occurred in only two Indian populations, Yakima and Peruvian, the frequencies being 0.018 and 0.025 , respectively. Ishimoto and Kuwata (1974) examined seven different Japanese populations and the allele frequencies of $G O T I^{*} 2$ and $G O T l^{*} 3$ were reported to be 0.0092 and 0.0025 , respectively, for all the populations combined. Frequencies of $G O T 1^{*} 2 H R 1$ in Hiroshima and Nagasaki children in this study were 0.015 and 0.012 , respectively. Though the frequencies of the GOTl*2 and $G O T I^{*} 2 H R I$ alleles are similar to each other, and the electrophoretic patterns of the 1-2 and 1-2HR1 phenotypes closely resemble one another, we are reluctant to conclude that the two alleles, GOTI*2 and $G O T 1^{*} 2 H R I$, are identical until the nucleotide sequences or the amino acid sequences of the gene products are shown to be identical. Since electrophoretic patterns, that is, mobilities and intensities of three bands, of 1-3NG1 and 1-4NG1 are very similar, 1-3 phenotypes encountered in other populations may include phenotypes identical with 1-3NG1 and/or 14NG1. The combined frequencies of $G O T I^{*} 3 N G I$ and $G O T I^{*} 4 N G I$ are 0.0031 and 0.0024 in Hiroshima and in Nagasaki, respectively. These values are similar to the frequency of $G O T l^{*} 3$ obtained by Ishimoto and Kuwata (1974) from seven Japanese populations combined, who noted that $G O T 1^{*} 3$ allele may occur at a lower frequency in the southern localities of Japan, though they did not have sufficient data to make this conclusion wholly convincing. We were unable to confirm their observation in our study since differences between Hiroshima and Nagasaki in the 
frequencies of $G O T 1^{*} 3 N G 1\left(\chi^{2}=1.12\right.$, D.F. $\left.=1,0.20<\mathrm{p}<0.30\right)$ or $G O T 1^{*} 4 N G 1$ $\left(\mathrm{z}^{2}=0.24, \mathrm{D} . \mathrm{F} .=1,0.50<\mathrm{p}<0.70\right)$ or in the combined frequencies of these two alleles $\left(\chi^{2}=1.16, \mathrm{D} . \mathrm{F} .=1,0.20<\mathrm{p}<0.30\right)$ are not statistically significant even though Nagasaki is located south-west of Hiroshima. Nevertheless, populations from Hiroshima and Nagasaki have been considered to be genetically different on the basis of significant differences in the frequencies of certain types of variants of phosphoglucomutase-1 (PGM1) and glucose phosphate isomerase (GPI) between the two cities (Satoh et al., 1984; Tanis et al., 1978). To explain the discrepancy in frequency of GOT1 variants compared with PGM1 and GPI, one may speculate that mutations producing GOTI*3NGI and GOTI*4NGI alleles as well as GOTI*2HRI allele probably occurred and spread among Mongoloid populations, and some of them subsequently migrated to the Japanese Archipelago, while mutations producing rare alleles of PGM1 or GPI might have occurred among peoples who migrated at later times to the Japanese Islands from southern Asia or southern Pacific area. Differences in frequencies of some alleles of PGM1 and GPI in Nagasaki compared to Hiroshima were considered to express the stronger influence of the southern migration stream into Nagasaki (Takahashi et al., 1982; Satoh et al., 1984).

Acknowledgement The authors wish to express their thanks to Mrs. C. Ueno, Miss N. Masunari and Mr. H. Omine for their excellent technical assistance.

\section{REFERENCES}

Beutler, E., Blume, K.G., Kaplan, J.C., Löhr, G.W., Ramot, B., and Valentine, W.N. 1977. International Committee for Standardization in Haematology: Recommended methods for red-cell enzyme analysis. Br. J. Haematol. 35: 331-340.

Bossé, T.R. and Donald, E.A. 1979. The vitamin B6 requirement in oral contraceptive users. I. Assessment by pyridoxal level and transferase activity in erythrocytes. Am. J. Clin. Nutr. 32: 1015-1023.

Chen, S.H. and Giblett, E.R. 1971. Genetic variation of soluble glutamic-oxaloacetic transaminase in man. Am. J. Hum. Genet. 23: 419-424.

Cinnamon, A.D. and Beaton, J.R. 1970. Biochemical assessment of vitamin B6 status in man. Am. J. Clin. Nutr. 23: 696-702.

Davidson, R.G., Cortner, J.A., Rattazzi, M.C., Ruddle, F.H., and Lubs, H.A. 1970. Genetic polymorphisms of human mitochondrial glutamic oxaloacetic transaminase. Science 169: 391-392.

Ferrell, R.E., Ueda, N., Satoh, C., Tanis, R.J., Neel, J.V., Hamilton, H.B., Inamizu, T., and Baba, K. 1977. The frequency in Japanese of genetic variants of 22 proteins. I. Albumin, ceruloplasmin, haptoglobin, and transferrin. Ann. Hum. Genet. 40: 407-418.

Gahr, M., Meves, H., and Schroter, W. 1979. Fetal properties in red blood cells of newborn infants. Pediatr. Res. 13: 1231-1236.

Hackel, E., Hopkinson, D.A., and Harris, H. 1972. Population studies on mitochondrial glutamateoxaloacetate transaminase. Ann. Hum. Genet. 35: 491-496.

International Committee for Standardization in Haematology. 1967. Recommendations for haemoglobinometry in human blood. Br. J. Haematol. 13 (Supple): 71-75.

Ishimoto, G. and Kuwata, M. 1974. Studies on human glutamic-oxaloacetic transaminase variation, including enzyme patterns in some non-human primates. Jpn. J. Human. Genet. 18:

Vol. 31, No. 1, 1986 
364-372.

Kimura, Y., Kaneko, J., Masunari, N., Takahashi, N., Fujita, M., Hazama, R., Goriki, K., and Satoh, C. 1981. Genetic variants of erythrocyte glutamate-oxaloacetate transaminase (soluble GOT) in Japanese populations (Hiroshima, Nagasaki), Jpn. J. Human. Genet. 26: 155.

Mohrenweiser, H.W., Fielek, S., and Wurzinger, K.H. 1981. Characteristics of enzymes of erythrocytes from newborn infants and adults: activity, thermostability and electrophoretic profiles as a function of cell age. Am. J. Hematol. 11: 125-136.

Raica, N. and Sauberlich, H.E. 1964. Blood cell transaminase activity in human vitamin B6 deficiency. Am. J. Clin. Nutr. 15:67-72.

Sass, M.D., Vorsanger, E., and Spear, P.W. 1964. Enzyme activity as an indicator of red cell age. Clin. Chim. Acta 10: 21-26.

Satoh, C., Neel, J.V., Yamashita, A., Goriki, K., Fujita, M., and Hamilton, H.B. 1983. The frequency among Japanese of heterozygotes for deficiency variants of 11 enzymes. Am. J. Hum. Genet. 35: 656-674.

Satoh, C., Takahashi, N., Masunari, N., Fujita, M., Goriki, K., Hazama, R., and Iwamoto, K. 1984. Electrophoretic variants of blood proteins in Japanese. I. Phosphoglucomutase-2. Jpn. J. Human Genet. 29: 89-104.

Satoh, C., Neel., J.V., Miura, A., Ueno, C., Arakawa, H., Omine, H., Goriki, K., and Fujita, M. 1985. Inherited thermostability variants of seven enzymes in a Japanese population. Ann. Hum. Genet. 49:11-22.

Takahashi, N., Neel, J.V., Satoh, C., Nishizaki, J., and Masunari, N. 1982. A phylogeny for the principal alleles of the human phosphoglucomutase-1 locus. Proc. Natl. Acad. Sci. USA. 79: 6636-6640.

Tanis, R.J., Ueda, N., Satoh, C., Ferrell, R.E., Kishimoto, S., Neel, J.V., Hamilton, H.B., and Ohno, N. 1978. The frequency in Japanese of genetic variants of 22 proteins. IV. Acid phosphatase, NADP-isocitrate dehydrogenase, peptidase $\mathrm{A}$, peptidase $\mathrm{B}$ and phosphohexose isomerase. Ann. Hum. Genet. 41: 419-428.

Teng, Y.S., Tan, S.G., Lopez, C.G., Ng, T., and Lie-Injo, L.E. 1978. Genetic markers in Malaysians: Variants of soluble and mitochondrial glutamic oxaloacetic transaminase and salivary and pancreatic amylase, phosphoglucomutase III and saliva esterase polymorphisms. Hum. Genet. 41: 347-354.

Toyomasu, T., Sakakibara, S., Kagamiyama, H., and Matsumoto, H. 1984. Genetic polymorphism of mitochondrial glutamate-oxaloacetate transaminase in Japanese. Hum. Genet. 69: 90-91.

Wurzinger, K.H. and Mohrenweiser, H.W. 1982. Studies on the genetic and non-genetic (physiological) variation of humanerythrocyte glutamic oxaloacetic transaminase. Ann. Hum. Genet. 46: 191-201, 